\title{
Emotional memory for central and peripheral details in children with callous-unemotional traits
}

Citation for published version (APA):

Thijssen, J., Otgaar, H., Meijer, E. H., Smeets, T., \& de Ruiter, C. (2012). Emotional memory for central and peripheral details in children with callous-unemotional traits. Behavioral Sciences \& the Law, 30(4), 506-515. https://doi.org/10.1002/bsl.2021

Document status and date:

Published: 01/01/2012

DOI:

$10.1002 / \mathrm{bsl} .2021$

Document Version:

Publisher's PDF, also known as Version of record

Document license:

Taverne

Please check the document version of this publication:

- A submitted manuscript is the version of the article upon submission and before peer-review. There can be important differences between the submitted version and the official published version of record.

People interested in the research are advised to contact the author for the final version of the publication, or visit the DOI to the publisher's website.

- The final author version and the galley proof are versions of the publication after peer review.

- The final published version features the final layout of the paper including the volume, issue and page numbers.

Link to publication

\footnotetext{
General rights rights.

- You may freely distribute the URL identifying the publication in the public portal. please follow below link for the End User Agreement:

www.umlib.nl/taverne-license

Take down policy

If you believe that this document breaches copyright please contact us at:

repository@maastrichtuniversity.nl

providing details and we will investigate your claim.
}

Copyright and moral rights for the publications made accessible in the public portal are retained by the authors and/or other copyright owners and it is a condition of accessing publications that users recognise and abide by the legal requirements associated with these

- Users may download and print one copy of any publication from the public portal for the purpose of private study or research.

- You may not further distribute the material or use it for any profit-making activity or commercial gain

If the publication is distributed under the terms of Article $25 \mathrm{fa}$ of the Dutch Copyright Act, indicated by the "Taverne" license above, 


\title{
Emotional Memory for Central and Peripheral Details in Children with Callous-Unemotional Traits
}

\author{
Jill Thijssen*, Henry Otgaar ${ }^{\dagger}$, Ewout H. Meijer ${ }^{\dagger}$, Tom Smeets ${ }^{\dagger}$ \\ and Corine de Ruiter ${ }^{\dagger}$
}

A limited number of studies have shown that adults and adolescents with psychopathic traits suffer from emotional memory impairment. The present study examined whether this finding could be replicated in a sample of children between 8 and 12 years of age with callous-unemotional $(C U)$ traits. Children with high $\mathrm{CU}$ traits $(n=24)$ were compared with children with low $\mathrm{CU}$ traits $(n=18)$ with regard to performance on a peripheral memory recognition test that examined memory for central and peripheral components of neutral and negative pictures. Results showed that overall recognition rates did not differ between the high- and low-CU groups. For negative pictures, both groups demonstrated better recognition of the central component at the expense of the peripheral component, while for neutral pictures, the peripheral component was better recognized than the central component. This study is the first to demonstrate that children with high CU traits do not suffer from an impaired emotional memory. Copyright $($ C) 2012 John Wiley \& Sons, Ltd.

According to the Diagnostic and Statistical Manual of Mental Disorders, 4th edn (Text Revision) (DSM-IV-TR; American Psychiatric Association, 2000), conduct disorder (CD) refers to children's and adolescents' recurrent and persistent rule-breaking behavior in which the basic rights of others or major age-appropriate societal norms or rules are violated. Children with $\mathrm{CD}$, for example, tend to frequently steal, vandalize, lie, and cause physical harm to other people or animals. A subset of children with CD is characterized by so-called callous-unemotional (CU) personality traits, which closely resemble the emotional detachment component of psychopathy in adult forensic samples (Frick, 2006; Frick, Cornell, Barry, Bodin, \& Dane, 2003). Although not all children with CU traits become psychopaths, they are at greater risk for developing psychopathy (Fontaine, McCrory, Boivin, Moffitt, \& Viding, 2011). Children with CU traits are characterized by low fear in combination with high impulsivity, are not truly concerned with other people's feelings, and typically do not feel bad or guilty when showing rule-breaking behavior. Furthermore, children with CU traits have more difficulty in identifying fearful and sad facial expressions (Blair, Colledge, Murray, \& Mitchell, 2001; Stevens, Charman, \& Blair, 2001; Woodworth \& Waschbusch, 2008) and show reduced psychophysiological responding to distressing and threatening pictures, films and words, which indicates reduced affective arousal (Anastassiou-Hadjicharalambous \& Warden, 2008; Blair, 1999; Kimonis, Frick, Fazekas,

*Correspondence to: Jill Thijssen, Forensic Psychology Section, Department of Clinical Psychological Science, Faculty of Psychology and Neuroscience, Maastricht University, P.O. Box 616, 6200 MD, Maastricht, the Netherlands. E-mail: Jill.Thijssen@maastrichtuniversity.nl

${ }^{\dagger}$ Forensic Psychology Section, Department of Clinical Psychological Science, Maastricht University 
\& Loney, 2006; Loney, Frick, Clements, Ellis, \& Kerlin, 2003). Collectively, these studies show that children with CU traits have a specific deficit in processing negative emotional stimuli (Frick, 2006).

To date, however, little is known about whether this deficit in processing negative stimuli also impacts memory performance. Generally, emotional events are remembered better than neutral ones (Buchanan, 2007; LaBar \& Cabeza, 2006). Moreover, research has demonstrated that high levels of arousal enhance memory for negative stimuli in particular (Cahill \& McGaugh, 1995; Steinmetz, Addis, \& Kensinger, 2010). Specifically, central details of an emotional event tend to be well remembered over time at the expense of memory for peripheral details (i.e., less contextually relevant or spatially peripheral to the attended event; see, e.g., Burke, Heuer, \& Reisberg, 1992; Christianson, 1992; Christianson, Loftus, Hoffman, \& Loftus, 1991; Heuer \& Reisberg, 1990; Levine \& Edelstein, 2009; Otani, Libkuman, Widner, \& Graves, 2007).

However, in contrast to normally functioning healthy individuals, people with psychopathic traits do not seem to exhibit enhanced memory for (negative) emotional material (Christianson et al., 1996; Dolan \& Fullam, 2005, 2010). For example, Christianson et al. (1996) showed that relative to non-psychopathic offenders, psychopathic offenders did not display enhanced memory for central emotionally negative details over peripheral details. In a similar vein, Dolan and Fullam (2005) found that psychopathic offenders were, in fact, worse at recalling emotional slides than healthy controls (for a replication study among conduct disordered adolescents, see Dolan \& Fullam, 2010). To the best of our knowledge, however, there are no studies investigating whether children with CU traits also display diminished memory for emotional stimuli. If one were, indeed, to find impairments in emotional memory in children with CU traits, this would provide valuable insights into why such children learn less from negative emotional experiences, such as being punished for misbehavior (see Dadds \& Salmon, 2003). Research has shown that children with CU traits are less responsive to effective parenting, because they respond with insufficient anxiety when confronted with their misbehavior (Hipwell et al., 2007; Oxford, Cavell, \& Hughes, 2003; Viding, Fontaine, Oliver, \& Plomin, 2009; Vitacco, Neumann, Ramos, \& Roberts, 2003; Wootton, Frick, Shelton, \& Silverthorn, 1997). The assumption is that they are less likely to remember the experience of being punished, which makes them less likely to inhibit their behavior in future situations in order to avoid the punishment.

Thus, the primary aim of the present study was to examine whether memory for central and peripheral components of neutral and emotionally negative pictures in children with high CU traits is impaired relative to children with low CU traits. Based on previous research, it was expected that memory for central details would be enhanced at the expense of memory for peripheral details overall (i.e., independent of CU traits or picture valence). Furthermore, for neutral pictures, we expected no differences between the high- and low-CU groups with respect to the memory-enhancing effect for central details relative to peripheral ones. However, for negative pictures it was expected that this central vs. peripheral memory ratio would be larger in the low-CU group than in the high-CU group.

\section{METHOD}

\section{Participants}

The current sample of children was recruited through elementary schools. Information and consent forms that explained the nature of the study, together with the Antisocial 
Process Screening Device (APSD) to assess psychopathic traits in children, were distributed at elementary schools. Parents were asked to sign the consent form, fill out the APSD and return them to the child's school, where they were collected. Children were allowed to participate only when they assented to the procedure and parental consent was obtained. This study was approved by the standing Ethical Committee of the Faculty of Psychology and Neuroscience, Maastricht University.

In total, parents of 77 children between 8 and 12 years of age $($ mean $=9.9)$ filled out the APSD and signed the consent form. To obtain extreme groups, we selected only the children with raw scores $\geq 6$ on the CU subscale of the APSD as the high-CU group $(n=24 ; 13$ male) and children with CU-subscale scores $\leq 2$ as the low CU group $(n=18$; 11 male). These two groups did not differ with respect to mean age [high-CU group: 10.3 years; low-CU group: 9.8 years; $t(40)=-1.15, p=0.26$ ] and gender distribution $\left[\chi^{2}(2)=0.68, p=0.65\right]$. In Table 1 , the mean scores of both groups on the APSD subscales are presented.

\section{Materials}

\section{APSD}

The APSD (Frick \& Hare, 2001) is a 20-item questionnaire aimed at assessing psychopathic traits in children and adolescents and is based on the Psychopathy ChecklistRevised (PCL-R; Hare, 1991). The APSD has to be completed by the child's parents or teachers. It consists of three dimensions: CU traits (six items), impulsivity (five items) and narcissism (seven items). All items are answered with 0 (not at all true), 1 (sometimes true), or 2 (definitely true). Examined in both community and clinical samples, the internal consistency of the three subscales ranged from 0.65 to 0.85 (Frick, Bodin, \& Barry, 2000). The APSD has been found to have good convergent and construct validity (Vitacco, Rogers, \& Neumann, 2003). The Dutch translation that was used in the present study has also been well validated (Bijttebier \& Decoene, 2009).

\section{Memory for Central and Peripheral Components}

To test the memory for central and peripheral components of neutral and negative pictures, we developed a peripheral memory test (PMT). Stimuli consisted of pictures of a single object (central component) surrounded by a gray frame in which a red symbol was presented in each corner (peripheral component). The original stimuli consisted of three pictures with a width by height of $259 \times 416$ pixels, 12 pictures of $416 \times 259$ pixels, four

Table 1. Mean scores, standard deviations, and significant differences between groups on the Antisocial Process Screening Device (APSD) subscales

\begin{tabular}{lcc}
\hline & Low-CU group & High-CU group \\
\hline Narcissism & $1.72(1.49)$ & $3.25(3.22)^{\star}$ \\
Impulsivity & $2.89(2.17)$ & $4.29(2.35)$ \\
Callous-unemotional & $1.33(.84)$ & $6.83(1.20)^{\star}$ \\
APSD total & $6.17(3.92)$ & $17.88(6.26)^{\star}$ \\
\hline
\end{tabular}

${ }^{\star} p<0.05$.

$\mathrm{CU}=$ callous-unemotional. 
pictures of $529 \times 340$ pixels, and one picture of $416 \times 416$ pixels. These stimuli were presented at $50 \%$ of their original size on a 15 -inch screen with a resolution of $1440 \times 900$ pixels.

A total of 20 pictures served as the central component: 10 neutral (pictures of a boot, lighthouse, locomotive, green traffic light, tree, bus, deer, fence, electric power pylon, and lamp), and 10 negative (aggressive dog, premature baby, hand with stitches, shark, weapon, black eye, crashed car, bloody knife, scary mask, and needle in an arm). Ten different symbols were used in the frame, with each symbol occurring once in a neutral and once in a negative picture, with varying orientation (see Figure 1 for an example).

The PMT consisted of three practice trials and 20 test trials ( 10 with a neutral and 10 with a negative picture). Children were instructed to take a good look at the whole picture, including the frame, and were asked to try to remember everything. They were also warned that the picture would be presented only for a short time. As can be seen in Figure 2, a fixation cross was presented first for $500 \mathrm{~ms}$. Next, the target picture plus the frame with symbols was presented for $1 \mathrm{~s}$, followed by a black screen for $10 \mathrm{~s}$. Afterwards, the original target picture was presented together with three similar distractor pictures. The child had to identify the correct picture by entering the number corresponding to the picture $(1,2,3,4)$. Next, the same procedure was followed for the symbol in which the correct orientation of the symbol (left, right, up, down) had to be chosen. Within each trial, the order of the forced choice recognition of the central and peripheral components was random -sometimes the central components were presented first and at other times the peripheral components were presented first. The intertrial interval was $2 \mathrm{~s}$. The order of the test trials was also random. The PMT was run using the Inquisit 3 program.

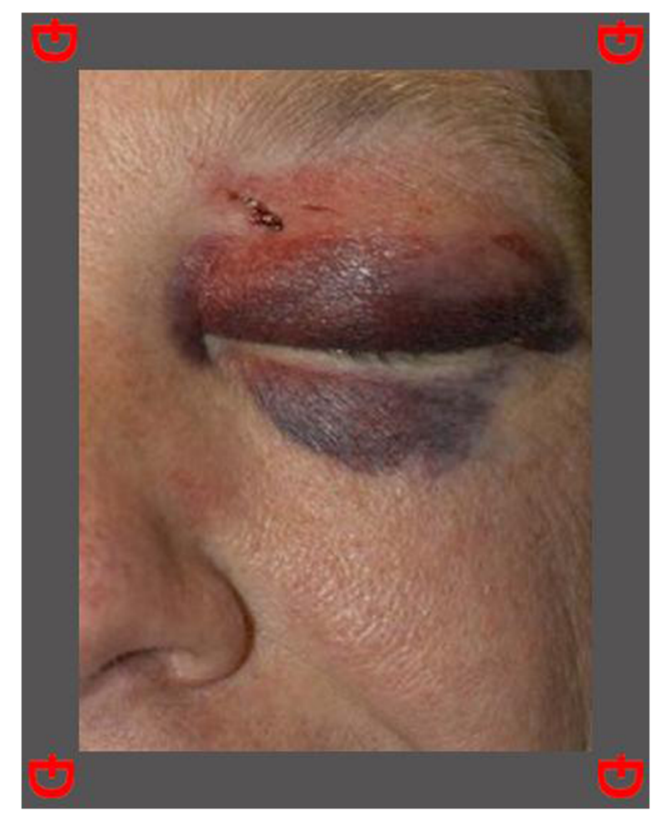

Figure 1. Example of a negative picture with symbol used in the peripheral memory test. 


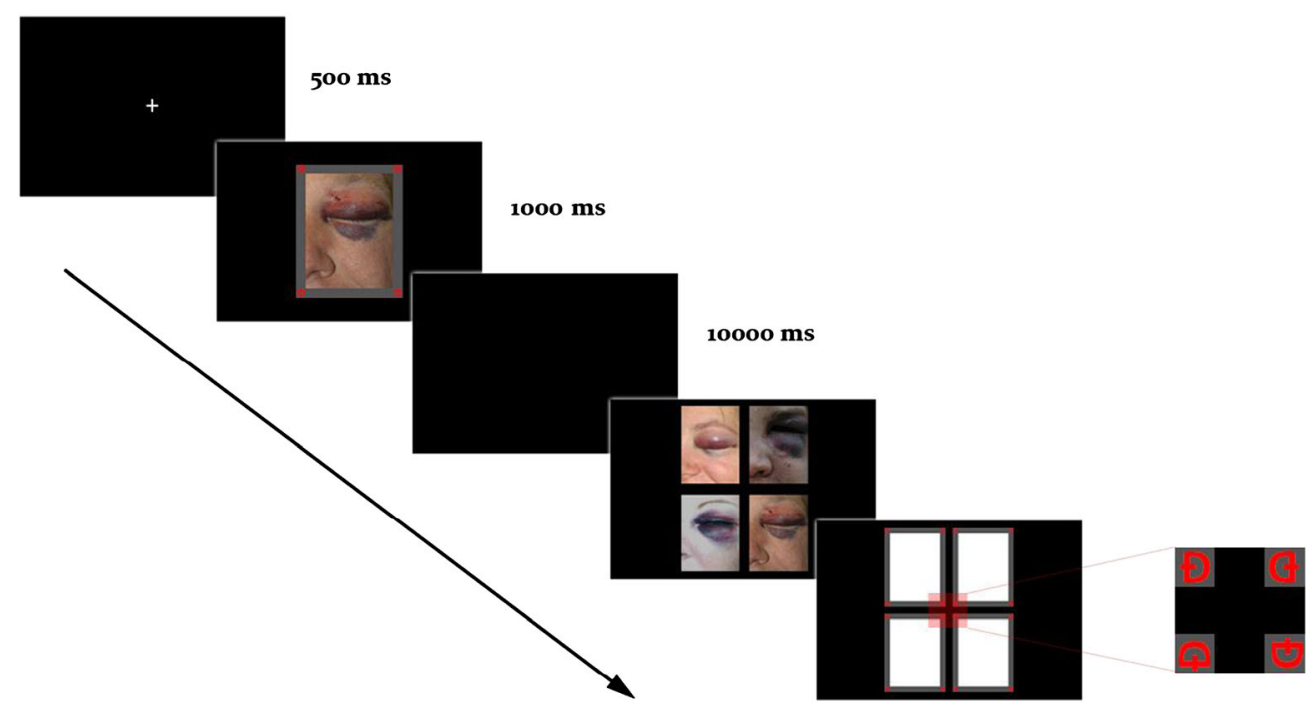

Figure 2. Timeline of a peripheral memory test trial.

\section{Pilot Data}

To check if the negative pictures were actually experienced as negative and the neutral ones as neutral, a group of children $(n=21)$ aged $7-12$ years rated the valence of the pictures on five-point Likert scales using smileys ( $1=$ very negative, $2=$ negative, $3=$ neutral, $4=$ positive, $5=$ very positive). The means of the neutral pictures and negative pictures were $3.43(\mathrm{SD}=0.35)$ and $1.89(\mathrm{SD}=0.30)$, respectively $[t(20)=20.68, p<0.01$, Cohen's $d=4.76]$. Furthermore, we checked if either the neutral or negative target pictures were easier to recognize than the other type. Children had to rate the similarity of the target picture between the distractor pictures on a five-point Likert scale, with higher scores indicating a higher degree of similarity between the pictures. There was a significant difference in similarity between the neutral and negative pictures, with a higher mean for the neutral pictures $[t(20)=3.19, p<0.01$, Cohen's $d=0.36]$. However, when piloting the PMT, children did not show longer reaction times for the recognition of neutral pictures. The mean reaction time was $5.89 \mathrm{~s}(\mathrm{SD}=1.94)$ for the neutral pictures and $6.09 \mathrm{~s}(\mathrm{SD}=2.00)$ for the negative pictures. This difference was not significant $[t(9)=-0.44, p=0.67]$.

\section{Design and Procedure}

The present experiment was a 2 (valence: neutral vs. negative) $\times 2$ (detail: central vs. peripheral) $\times 2$ (group: low CU vs. high CU) split-plot design, with the last factor as the between-subjects factor.

The selected children were seated comfortably in front of a computer in a quiet room at the child's school. The PMT was always administered in the afternoon to control for potential time of day effects on, for example, fatigue, attention and concentration. The experimenter explained the test by reading the instructions presented on the computer 
together with the child. After the three practice trials, the experimenter asked the child whether the procedure of the test was clear before starting with the test trials. The PMT took between 10 and $15 \mathrm{~min}$. Afterwards, children were given a small present in return for their participation.

\section{RESULTS}

Figure 3 shows the mean proportion of correctly recognized central and peripheral components for the neutral and negative pictures for the two groups. To examine these differences in correct recognition, a repeated measures analysis of variance (ANOVA) was conducted with group (high-CU group vs. low-CU group) as the between-subjects factor and valence (neutral vs. negative) and detail (central vs. peripheral) as withinsubjects factors. The group $\times$ valence $\times$ detail interaction was not statistically significant $[F(1,40)=0.01, p=0.94]$. However, a significant interaction between valence and detail was found $\left[F(1,40)=34.87, p<0.01, \eta_{\mathrm{p}}^{2}=0.47\right]$. To identify the differences between levels of valence and detail, simple effects analyses were performed. For the neutral pictures, the peripheral component was significantly better recognized than the central component $[t(41)=-3.03, p<0.01$, Cohen's $d=-0.68]$. However, for the negative pictures, the central component was significantly better recognized than the peripheral component $[t(41)=4.15, p<0.01$, Cohen's $d=0.93]$. Furthermore, there was a significant difference between the central components for the neutral and negative pictures. The central component was better recognized for negative pictures than for neutral pictures $[t(41)=-5.32, p<0.01$, Cohen's $d=-1.03]$. The peripheral component was significantly better recognized for the neutral pictures than for the negative pictures

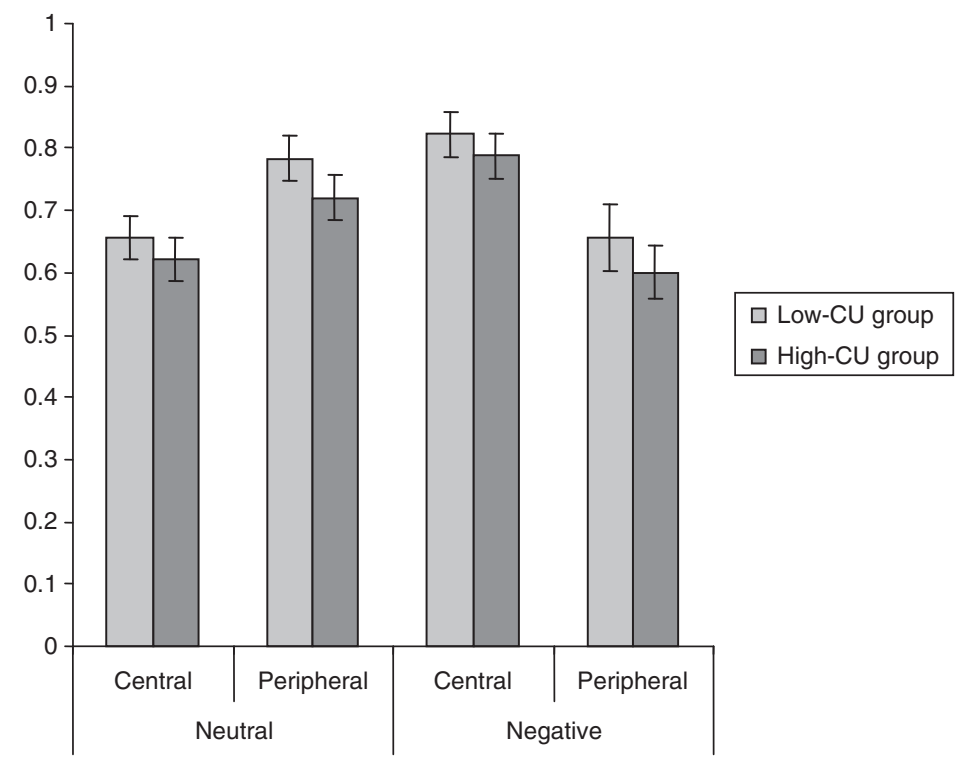

Figure 3. Mean proportion of correctly recognized central and peripheral components for the neutral and negative pictures. 
$[t(41)=3.19, p<0.01$, Cohen's $d=0.64]$. None of the other interactions or main effects reached significance.

Differences in latency were also examined, using a repeated-measures ANOVA with group (high-CU group vs. low-CU group) as the between-subjects factor and valence (neutral vs. negative) and detail (central vs. peripheral) as within-subjects factors. Again, the group $\times$ valence $\times$ detail interaction was not significant $[F(1,40)=2.34, p=0.13]$. Only a significant main effect was found for detail $\left[F(1,40)=34.35, p<0.01, \eta_{\mathrm{p}}^{2}=0.49\right]$ with longer reaction times for the central components $(M=5783 \mathrm{~ms})$ than for the peripheral components $(M=4398 \mathrm{~ms})$. No other main effects or interactions were significant.

\section{DISCUSSION}

Previous studies have found that adults and adolescents with psychopathic traits have a memory impairment for emotional stimuli (Christianson et al., 1996; Dolan \& Fullam, 2005,2010 ). The present study examined whether this finding could be replicated in a non-clinical sample of children with high and low CU traits. Interestingly, the results of this study showed no difference in emotional memory between the high- and low-CU groups.

Our PMT was successful in replicating the peripheral memory effect found in previous studies (e.g., Burke et al., 1992; Christianson, 1992; Christianson et al., 1991; Heuer \& Reisberg, 1990; Levine \& Edelstein, 2009; Otani et al., 2007). For the neutral pictures, the peripheral component was better recognized than the central component, while for the negative pictures the central component was better recognized than the peripheral component. Interestingly, the peripheral component was better recognized for the neutral pictures than for the negative pictures. The 10 symbols used as peripheral components were the same for both the neutral and negative pictures. Only the orientation of the symbol varied. Therefore, the difference in recognition of the peripheral components could only be explained by the valence of the central picture. Attention is being drawn to the negative picture, at the expense of the attention paid to the symbol.

Generally, central details receive more attention than peripheral details, which would lead to a better memory for the central details than for peripheral details (Riggs, McQuiggan, Farb, Anderson, \& Ryan, 2011). Contrary to our expectations, it was found that the peripheral component was better recognized than the central component of neutral pictures. In the present study, children were explicitly instructed to look at both the picture (central component) and the frame with the symbols (peripheral component). When both components received the same amount of attention, it seems logical that the peripheral component was better recognized than the central component of neutral pictures, as the central picture is more complex than a simple symbol. For emotionally negative pictures, attention is drawn to the central component despite the instruction to look at both components. Therefore, the central component receives more attention than the peripheral component, which leads to a better memory for the central component at the expense of memory for the peripheral component (Glass \& Newman, 2009). Although attention is not the only condition contributing to better memory for emotional details, it is a necessary one (Christianson et al., 1991; Kramer, Buckhout, \& Eugenio, 1990).

A possible explanation for not finding a difference in emotional memory between the high- and low-CU groups could be that the impairment in emotional memory has not developed yet in children of this age. Dolan and Fullam (2010) suggest that the deficit 
in emotional memory in people with psychopathic traits is reasonably stable across the lifespan. However, this does not seem to be the case for children with CU traits. In a recent study from our laboratory, we also found that children with low and high CU traits did not differ on true recall for both neutral and negative word lists (Thijssen, Otgaar, Howe, \& de Ruiter, 2012). Salekin, Debus, and Jackson (2008) noted that with regard to performance tasks, the observed association between emotional processing deficits and psychopathy in adults is not as robust in children. Therefore, the disorder might not fully develop until adulthood and the impaired emotional processing in children with high CU traits may thus not have affected memory for emotional material yet.

Previous studies focusing on central and peripheral memory have mainly used pictures from the International Affective Picture System (IAPS; Lang, Bradley, \& Cuthbert, 1998). However, the problem with such studies is that it is difficult to ascertain what the central and peripheral details are exactly. In our PMT, this distinction was clear and it was easy to manipulate the peripheral details. A limitation of the PMT could be the central pictures that were used. Since different pictures were used in the neutral and negative conditions, it cannot be ruled out that the negative pictures might indeed be easier to recognize than the neutral pictures. In the pilot study, it was found that the distractor pictures for the negative pictures were less similar than the distractor pictures for the neutral pictures, which indicates that the negative pictures are easier to distinguish than the neutral pictures.

Several possible explanations could be given for why the present study was not able to replicate previous findings regarding emotional memory of adolescents and adults with psychopathic traits (Christianson et al., 1996; Dolan \& Fullam, 2005, 2010). First, this might have to do with the fact that the present study used a non-clinical sample. Specifically, while the previous studies used clinical samples, the low- and high-CU groups in the current study were selected from the general population. Thus, even though our groups differed significantly in CU traits, the high-CU group may nonetheless be difficult to compare with a high-CU group selected from a clinical population in which CU traits are expected to be more extreme. Second, previous studies used a different memory task in that they used a slideshow together with a short narrative to measure memory for central and peripheral details, while in the present study unrelated pictures were used. Although speculative, it could be that in the previous studies, the memory test with narratives evoked more relational processing (Hunt \& Einstein, 1981), while our memory test in the current study likely elicited more item-specific processing. Since people with psychopathic traits seem to have deficits in their relational processing of emotional memories, one might argue that our memory test was not sensitive enough to detect these relational processing deficits. Finally, our sample size was fairly small, which may have led to insufficient power to detect small between-group differences.

In summary, the present study did not find a difference in emotional memory between children with high and low CU traits. However, we did show that both groups had a better memory for the central component of negative pictures at the expense of the peripheral component, while their memory for neutral pictures was better for the peripheral component than for the central component. This finding suggests that the PMT is a useful tool to examine the memory-narrowing effect found in previous studies. Moreover, based on the results of the present study, children with CU traits do not seem to have a deficit in emotional memory. This suggests that impairments in emotional memory may not be an explanation for why children with CU traits are less responsive to effective parental correction. 


\section{ACKNOWLEDGEMENTS}

We thank Marjolijn O’Connor and Ymke Peulen for their assistance in this study.

\section{REFERENCES}

American Psychiatric Association. (2000). Diagnostic and statistical manual of mental disorders, (4th ed, text rev.). Washington, DC: American Psychiatric Association.

Anastassiou-Hadjicharalambous, X., \& Warden, D. (2008). Physiologically-indexed and self-perceived affective empathy in conduct-disordered children high and low on callous-unemotional traits. Child Psychiatry and Human Development, 39, 503-517.

Bijttebier, P., \& Decoene, S. (2009). Assessment of psychopathic traits in children and adolescents: Further validation of the Antisocial Process Screening Device and the Childhood Psychopathy Scale. European Fournal of Psychological Assessment, 25, 157-163.

Blair, R. J. R. (1999). Responsiveness to distress cues in the child with psychopathic tendencies. Personality and Individual Differences, 27, 135-145.

Blair, R. J. R., Colledge, E., Murray, L., \& Mitchell, D. G. V. (2001). A selective impairment in the processing of sad and fearful expressions in children with psychopathic tendencies. Fournal of Abnormal Child Psychology, 29, 491-498.

Buchanan, T. W. (2007). Retrieval of emotional memories. Psychological Bulletin, 133, 761-779.

Burke, A., Heuer, F., \& Reisberg, D. (1992). Remembering emotional events. Memory \& Cognition, 20, $277-290$.

Cahill, L., \& McGaugh, J. L. (1995). A novel demonstration of enhanced memory associated with emotional arousal. Consciousness and Cognition, 4, 410-421.

Christianson, S.-Ã. (1992). Emotional stress and eyewitness memory: A critical review. Psychological Bulletin, 112, 284-309.

Christianson, S.-Ã., Forth, A. E., Hare, R. D., Strachan, C., Lidberg, L., \& Thorell, L.-H. (1996). Remembering details of emotional events: A comparison between psychopathic and nonpsychopathic offenders. Personality and Individual Differences, 20, 437-443.

Christianson, S.-Ã., Loftus, E. F., Hoffman, H., \& Loftus, G. R. (1991). Eye fixations and memory for emotional events. Fournal of Experimental Psychology. Learning, Memory, and Cognition, 17, 693-701.

Dadds, M. R., \& Salmon, K. (2003). Punishment insensitivity and parenting: Temperament and learning as interacting risks for antisocial behavior. Clinical Child and Family Psychology Review, 6, 69-86.

Dolan, M. C., \& Fullam, R. (2005). Memory for emotional events in violent offenders with antisocial personality disorder. Personality and Individual Differences, 38, 1657-1667.

Dolan, M. C., \& Fullam, R. (2010). Emotional memory and psychopathic traits in conduct disordered adolescents. Personality and Individual Differences, 48, 327-331.

Fontaine, N. M. G., McCrory, E. J. P., Boivin, M., Moffitt, T. E., \& Viding, E. (2011). Predictors and outcomes of joint trajectories of callous-unemotional traits and conduct problems in childhood. fournal of Abnormal Psychology, 120, 730-742.

Frick, P. J. (2006). Developmental pathways to conduct disorder. Child and Adolescent Psychiatric Clinics of North America, 15, 311-331.

Frick, P. J., Bodin, S. D., \& Barry, C. T. (2000). Psychopathic traits and conduct problems in community and clinic-referred samples of children: Further development of the Psychopathy Screening Device. Psychological Assessment, 12, 382-393.

Frick, P. J., Cornell, A. H., Barry, C. T., Bodin, S. D., \& Dane, H. E. (2003). Callous-unemotional traits and conduct problems in the prediction of conduct problem severity, aggression, and self-report of delinquency. fournal of Abnormal Child Psychology, 31, 457-470.

Frick, P. J., \& Hare, R. D. (2001). Antisocial Process Screening Device. Toronto: Multi-Health Systems.

Glass, S. J., \& Newman, J. P. (2009). Emotion processing in the criminal psychopath: The role of attention in emotion-facilitated memory. Fournal of Abnormal Psychology, 118, 229-234.

Hare, R. D. (1991). Manual for the Hare Psychopathy Checklist-revised. Toronto: Multi-Health Systems.

Heuer, F., \& Reisberg, D. (1990). Vivid memories of emotional events: The accuracy of remembered minutiae. Memory \& Cognition, 18, 496-506.

Hipwell, A. E., Pardini, D. A., Loeber, R., Sembower, M., Keenan, K., \& Stouthamer-Loeber, M. (2007). Callous-unemotional behaviors in young girls: Shared and unique effects relative to conduct problems. fournal of Clinical Child and Adolescent Psychology, 36, 293-304.

Hunt, R. R., \& Einstein, G. O. (1981). Relational and item-specific information in memory. Fournal of Verbal Learning \& Verbal Behavior, 20, 497-514.

Kimonis, E. R., Frick, P. J., Fazekas, H., \& Loney, B. R. (2006). Psychopathy, aggression, and the processing of emotional stimuli in non-referred girls and boys. Behavioral Sciences E the Law, 24, 21-37. 
Kramer, T. H., Buckhout, R., \& Eugenio, P. (1990). Weapon focus, arousal, and eyewitness memory: Attention must be paid. Law and Human Behavior, 14, 167-184.

LaBar, K. S., \& Cabeza, R. (2006). Cognitive neuroscience of emotional memory. Nature Reviews Neuroscience, 7 , 54-64.

Lang, P. J., Bradley, M. M., \& Cuthbert, B. N. (1998). International affective picture system (IAPS): Technical manual and affective ratings. Gainesville: Centre for research in psychophysiology, University of Florida.

Levine, L. J., \& Edelstein, R. S. (2009). Emotion and memory narrowing: A review and goal-relevance approach. Cognition and Emotion, 23, 833-875.

Loney, B. R., Frick, P. J., Clements, C. B., Ellis, M. L., \& Kerlin, K. (2003). Callous-unemotional traits, impulsivity, and emotional processing in adolescents with antisocial behavior problems. Fournal of Clinical Child and Adolescent Psychology, 32, 66-80.

Otani, H., Libkuman, T. M., Widner, R. L., Jr., \& Graves, E. I. (2007). Memory for emotionally arousing stimuli: A comparison of younger and older adults. The fournal of General Psychology, 134, $23-42$.

Oxford, M., Cavell, T. A., \& Hughes, J. N. (2003). Callous/unemotional traits moderate the relation between ineffective parenting and child externalizing problems: A partial replication and extension. fournal of Clinical Child and Adolescent Psychology, 32, 577-585.

Riggs, L., McQuiggan, D. A., Farb, N., Anderson, A. K., \& Ryan, J. D. (2011). The role of overt attention in emotion-modulated memory. Emotion, 11, 776-785.

Salekin, R. T., Debus, S. A., \& Jackson, R. (2008). Assessing child and adolescent psychopathy. In Learning forensic assessment. (pp. 347-383). New York, NY US: Routledge/Taylor \& Francis Group.

Steinmetz, K. R. M., Addis, D. R., \& Kensinger, E. A. (2010). The effect of arousal on the emotional memory network depends on valence. NeuroImage, 53, 318-324.

Stevens, D., Charman, T., \& Blair, R. J. R. (2001). Recognition of emotion in facial expressions and vocal tones in children with psychopathic tendencies. The fournal of Genetic Psychology, 162, 201-211.

Thijssen, J., Otgaar, H., Howe, M. L., \& de Ruiter, C. (2012). Emotional true and false memories in children with callous-unemotional traits: Article submitted for publication.

Viding, E., Fontaine, N. M. G., Oliver, B. R., \& Plomin, R. (2009). Negative parental discipline, conduct problems and callous-unemotional traits: Monozygotic twin differences study. The British fournal of Psychiatry, 195, 414-419.

Vitacco, M. J., Neumann, G. S., Ramos, V., \& Roberts, M. K. (2003). Ineffective parenting: A precursor to psychopathic traits and delinquency in Hispanic females. Annals of the New York Academy of Sciences, 1008, 300-303.

Vitacco, M. J., Rogers, R., \& Neumann, C. S. (2003). The Antisocial Process Screening Device: An examination of its construct and criterion-related validity. Assessment, 10, 143-150.

Woodworth, M., \& Waschbusch, D. (2008). Emotional processing in children with conduct problems and callous/unemotional traits. Child: Care, Health and Development, 34, 234-244.

Wootton, J. M., Frick, P. J., Shelton, K. K., \& Silverthorn, P. (1997). Ineffective parenting and childhood conduct problems: The moderating role of callous-unemotional traits. Fournal of Consulting and Clinical Psychology, 65, 301-308. 